\title{
Identifying adherent patients to newly initiated statins using previous adherence to chronic medications
}

\author{
Zahra Majd, PharmD; Anjana Mohan, MPharm; Rutugandha Paranjpe, MS; \\ and Susan M Abughosh, PhD
}

\section{What is already known about this subject}

- Despite well-established benefits, statin adherence rates are suboptimal.

- Targeting medication adherence interventions at potential nonadherent patients will increase

- Adding information from past medication adherence to administrative claims data improves predictability of the models identifying nonadherent patients. their efficiency.

\section{What this study adds}

- Past adherence to angiotensinconverting enzyme inhibitors, angiotensin II receptor blockers, and/ or oral antidiabetic drugs is strongly associated with future adherence to statins within 12 months of treatment initiation.

- Using previous adherence to chronic medications, health care providers and payers could identify statin new users likely to be nonadherent at the time of treatment initiation and develop interventions to enhance future adherence.

\section{Author affiliations}

Zahra Majd, PharmD; Anjana Mohan, MPharm; Rutugandha Paranjpe, MS; and Susan M Abughosh, PhD, Department of Pharmaceutical Health Outcomes and Policy, University of Houston College of Pharmacy, Houston, TX.

\section{AUTHOR CORRESPONDENCE:}

Susan M Abughosh, 832.842.8395; smabugho@central.uh.edu

J Manag Care Spec Pharm. 2021;27(2):186-97

Copyright $@ 2021$, Academy of Managed Care Pharmacy. All rights reserved.

controlling for various demographic and clinical characteristics.

betic drugs (OADs)

BACKGROUND: Statins are one of the most frequently prescribed medications in the United States. Despite well-documented benefits in managing hyperlipidemia and reducing cardiovascular risks, statin adherence remains suboptimal. Several effective interventions have been implemented to improve adherence to statins. However, identifying patients who are at risk for developing poor medication adherence at the time of treatment initiation could assist in planning early targeted interventions. Studies have suggested that previous adherence to chronic medications is a strong predictor of future adherence to newly initiated medications.

OBJECTIVE: To investigate patients' adherence to newly initiated statins by measuring previous adherence to angiotensin-converting enzyme inhibitors (ACEIs), angiotensin II
METHODS: A retrospective cohort study was conducted using administrative claims data from January 2016 to May 2018. New statin initiators were identified and included in the study if they were continuously enrolled in the health plan and had at least 1 prescription for ACEIs, ARBs, or OADs 1 year before statin initiation (pre-index period). Baseline adherence to ACEIs/ARBs, OADs, or both was calculated during a 1-year pre-index period using proportion of days covered (PDC) and defined as $P D C \geq 0.80$. Adherence to statins was assessed 1 year after statin initiation and was the primary outcome, with a PDC $\geq 0.80$ considered as adherent. Patient demographics were measured during the pre-index period. Multivariable logistic regression was conducted for each cohort separately to determine an association between baseline adherence and future statin adherence
RESULTS: 1,223 ACEI/ARB users, 714 OAD users, and 452 concomitant ACEl/ARB and OAD users were identified. In the regression model, adherence to baseline medications was significantly associated with 1-year adherence to statins (ACEI/ARB users: $\mathrm{OR}=1.75,95 \% \mathrm{Cl}=1.37-2.25$; OAD users: $\mathrm{OR}=2.02,95 \% \mathrm{Cl}=1.46-2.79$; concomitant ACEI/ARB and OAD users: OR $=1.73,95 \%$ $\mathrm{Cl}=1.16-2.58)$.

CONCLUSIONS: Past adherence to baseline medications may predict future adherence to newly initiated statins. Identifying patients likely to become nonadherent during treatment initiation could enable health care providers in recognizing individuals at risk of nonadherence and intervene earlier to enhance future adherence. 
Statins are one of the highest prescribed class of drugs in the United States. A nationally representative data analysis reported that more than $25 \%$ of U.S. individuals aged over 40 years were prescribed statins from 2012 to 2013., According to recent recommendations by the American College of Cardiology/American Heart Association (AHA), the number of patients indicated for statin therapy is expected to rise. $^{3}$ AHA recommends statins as a cornerstone medication for preventing cardiovascular events such as stroke, myocardial infarction, and coronary artery disease. ${ }^{4}$ Statins have been the mainstay of lipid-lowering therapy over the past decades. ${ }^{3}$ Despite well-established benefits in managing dyslipidemia and reducing risks for cardiovascular mortality and morbidity at a low cost, ${ }^{5-11}$ statin adherence rates are still suboptimal. Literature indicates that about $50 \%$ of patients discontinue statin therapy within a year of treatment initiation, and this number grows over time. ${ }^{12-17}$ This trend in poor adherence is in line with key findings of the Centers for Disease Control and Prevention, which reports that approximately $50 \%$ of the patients are nonadherent to their medications at any given time..$^{18}$

Poor medication adherence is a significant and challenging public health issue that has been identified as the leading cause of preventable morbidity, mortality, and health care costs. ${ }^{19}$ Although some successful interventions have been designed to improve adherence, ${ }^{20-24}$ it is widely acknowledged that these interventions should be targeted to appropriate patients and prioritize those who may benefit from it. ${ }^{25}$ According to a recent systematic review, almost all the clinical trials assessing the effect of interventions on statin adherence recruited patients without previous adherence problems, which may not be a feasible and cost-effective approach in larger scales. ${ }^{26}$ Given the limited time and resources for all stakeholders involved in the development and implementation of adherence programs, it is crucial to identify patients who are likely to fail treatment due to poor medication adherence in the future. This will further help clinicians, pharmacists, and other health care providers implement targeted interventions, preventing early discontinuation and maximizing efficacy of the treatment. ${ }^{27}$ However, identifying individuals who require such interventions has remained challenging.

Several approaches were implemented by earlier research to predict medication-taking behavior for statins, using nonmodifiable and modifiable factors. While age, gender, ethnicity, and comorbidity are nonmodifiable patient factors associated with adherence, patients' beliefs, attitudes, and behaviors are considered potential modifiable predictors for adherence. ${ }^{28}$ First, previous observational studies used patients' demographics, socioeconomic status, and regimen complexity to predict future adherence. These factors were successful in predicting patients' adherence. ${ }^{29,30}$ However, they could not strongly discriminate between the nonadherent and adherent cohort. ${ }^{31,32}$ Second, past prescription refill behavior was suggested as a better predictor for statin adherence compared with patient medication-taking health beliefs among patients enrolled in a national managed care plan. ${ }^{33}$ Third, Franklin et al. (2015) used group-based trajectory modeling to predict a 12-month trajectory pattern by incorporating initial patterns of refill among statin initiators. ${ }^{34}$ In this study, Franklin et al. reported that statinfilling behavior during the 2-4 months after treatment initiation strongly predicted future adherence trajectory in Medicare beneficiaries aged 65 years and older. ${ }^{34}$ Finally, previous adherence to medications prescribed for other chronic conditions, including antihypertensives, antidiabetics, anticoagulants, and antidepressants, was measured to predict future adherence to statins using administrative claims data. ${ }^{35-37}$ Results from these studies suggested that adding measures of past adherence to chronic medications could enhance predictability of the models compared with other models using baseline clinical factors; therefore, it may help identify patients at a higher risk of nonadherence.

The purpose of this study was to investigate patients' adherence to newly initiated statins by measuring previous adherence to common medications used for chronic conditions, including angiotensin-converting enzyme inhibitors (ACEIs), angiotensin II receptor blockers (ARBs), and oral antidiabetic drugs (OADs). The hypothesis was that patients who are adherent to their past chronic medication use will show better adherence to newly initiated statins over the first 12 months. In addition to the frequent use of ACEIs/ ARBs and OADs in patients who are prescribed statins, these medications have been selected for the baseline adherence measures, since adherence to them is part of the Centers for Medicare \& Medicaid Services (CMS) Star Rating Program to measure health plan performance. ${ }^{38,39}$

\section{Methods}

\section{STUDY DESIGN AND DATA SOURCES}

A retrospective cohort study was conducted using administrative claims data from patients enrolled in a Texas-based Medicare Advantage plan between January 2016 and May 2018. Several data files from the health plan were used in the analysis, including membership and member summary, medical claims, and pharmacy claim files. Membership files contained demographic information and CMS risk scores for patients. Medical claims included diagnostic information in the form of International Classification of Diseases, Tenth Revision, Clinical Modification (ICD-10-CM) codes and 


\section{FIGURE 1 Study Design}

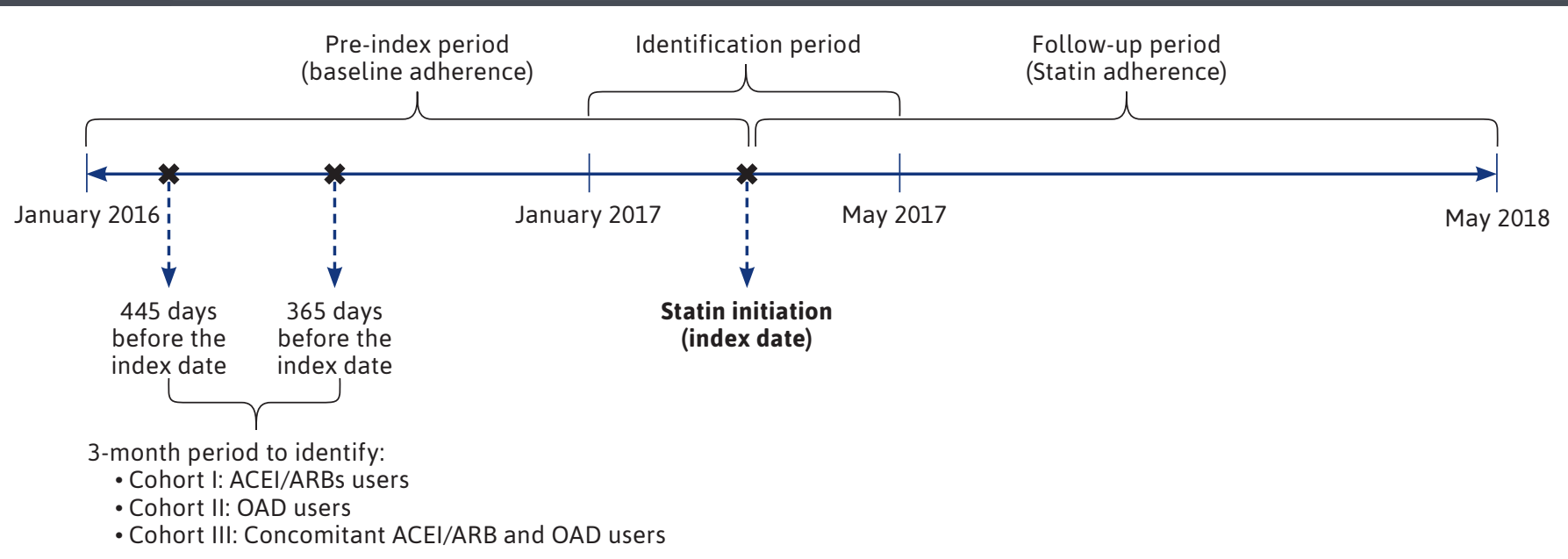

$A C E I=$ angiotensin-converting enzyme inhibitor; $A R B=$ angiotensin $\mid I$ receptor blocker; $O A D=$ oral antidiabetic drug.

procedure information in the form of Current Procedural Terminology codes for outpatient encounters. Pharmacy claims included patient and drug identifying information, fill dates, dosage information, and days supplied for each prescription.

This study was approved by the Institutional Review Board at the University of Houston.

\section{STUDY POPULATION}

Using pharmacy claims, all patients who newly initiated statins from January 2017 until the end of May 2017 were identified (identification period). The date of statin treatment initiation during the identification period was determined as the index date. One year before the index date was defined as the pre-index period. Patients were followed for 1 year after the index date, which was considered as the follow-up period. New statin users were identified if they did not have any previous prescription for statins within 180 days before the index date. ${ }^{34}$ Statin initiators were included in the study if (a) they had at least 1 pharmacy claim for ACEIs, ARBs, or OADs during the 3-month period between 455 and 365 days before the index date and (b) they had continuous enrollment over the entire study period. Patients were excluded if they had contraindications for ACEI/ARB use, which included angioedema, hyperkalemia, and renal artery stenosis, during the pre-index period or for statin use that included cirrhosis, rhabdomyolysis, and end-stage renal disease during the follow-up period, identified by ICD-10-CM codes. The study categorized patients into 3 separate cohorts based on their baseline medication use: cohort I-patients who had any prescriptions for ACEI or ARB medications; cohort II-patients who had any prescriptions for OADs; and cohort III-patients who had any prescriptions for ACEIs/ARBs and OADs. The study design is illustrated in Figure 1.

\section{OUTCOME MEASUREMENT}

Adherence to statins was the outcome of interest for this study and was measured using proportion of days covered (PDC) during the 1-year follow-up period. One-year PDC was calculated as the total number of follow-up days covered with dispensed medications divided by the total number of days in the follow-up period (360 days). ${ }^{40,41}$ PDC was dichotomized to categorize patients as "statin adherent" $(\geq 0.80)$ and "statin nonadherent" $(<0.80)$ groups.

\section{BASELINE MEASUREMENTS}

Baseline adherence was the primary explanatory variable of the study and was measured separately for patients in each cohort during the 1-year pre-index period using PDC. Adherence was defined as 1-year PDC $\geq 0.80$ for ACEI/ARB use in cohort I and for OAD use in cohort II. In the third cohort, patients were considered adherent if they had 1-year PDC $\geq 0.80$ for both ACEI/ARB use and OAD use. ${ }^{42}$ Since adherence was measured in accordance to pharmacologic classes and not individually, switching was allowed within drug categories, as well as between ACEIs and ARBs.

Patient demographics and clinical characteristics were measured during the pre-index period and conceptualized 


\section{FIGURE 2 Cohort Formation}

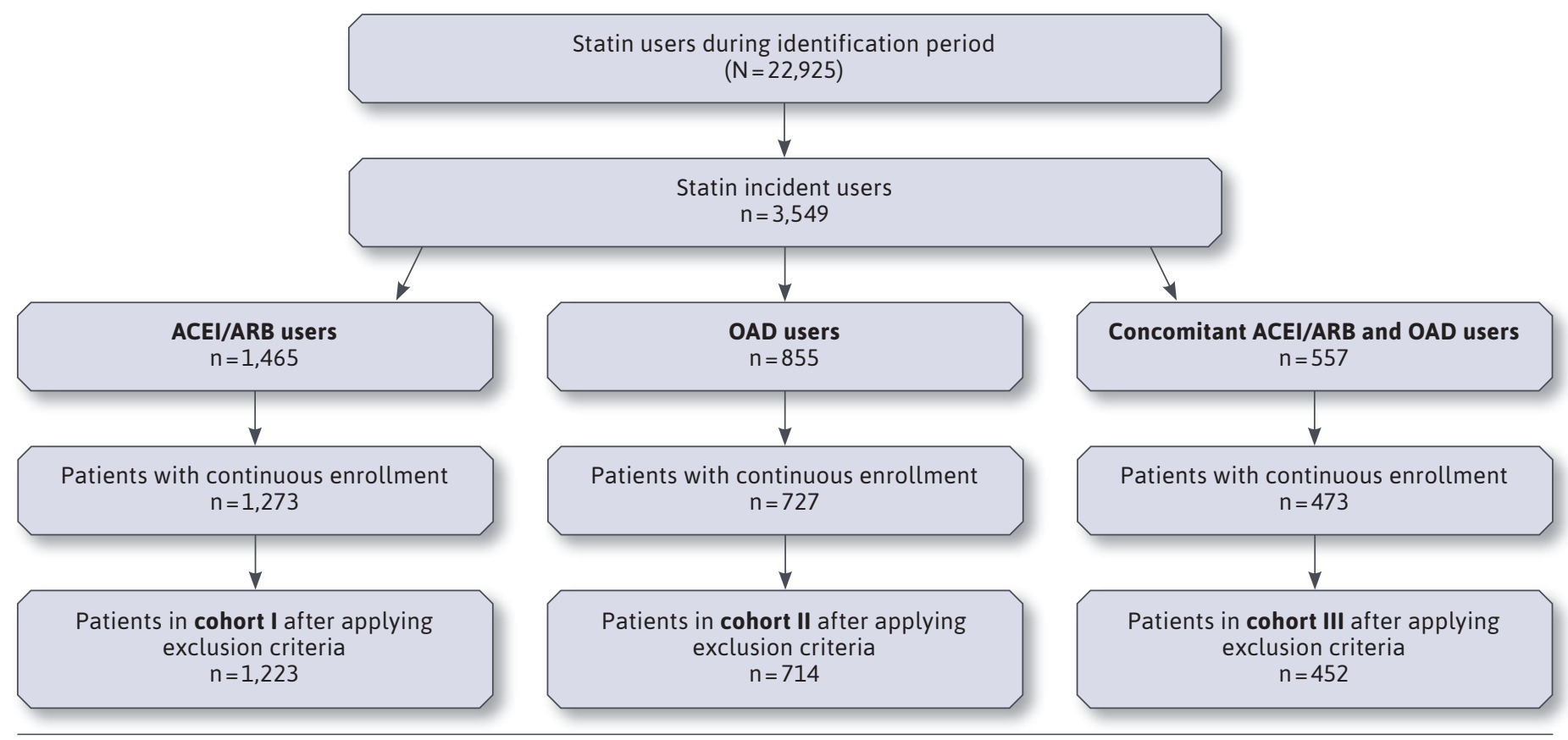

$A C E I=$ angiotensin-converting enzyme inhibitor; $A R B=$ angiotensin II receptor blocker; $O A D=$ oral antidiabetic drug

using Andersen's behavioral model (ABM). Based on ABM, determinants of an individual's health service utilization are categorized as predisposing, enabling, and need characteristics. ${ }^{43}$ In this study, predisposing characteristics included age and gender, enabling characteristics included low-income subsidy (given to eligible Medicare beneficiaries with limited income and resources and helps them with prescription drug costs), and need characteristics included comorbidities identified by ICD-10-CM codes, number of unique medications on the index date (apart from statin), CMS risk score, and previous hospitalizations. ${ }^{44}$ The CMS risk score is an indicator for medication burden and disease severity and consists of 189 disease classifications that are provided in Medicare Advantage plan data. ${ }^{12,45,46}$

\section{STATISTICAL ANALYSIS}

Descriptive analysis was performed to summarize patient demographics and clinical characteristics. Group differences were assessed using chi-square tests for categorical variables and t-tests for continuous variables. A multivariable logistic regression was conducted to investigate the association between adherence to the baseline medication and future statin adherence within each cohort, controlling for various demographic and clinical characteristics.
Covariates included in the regression model were gender; age category ( $<70$ years, $70-79$ years, $\geq 80$ years); health plan (low-income subsidy vs. no subsidy); comorbidities such as dementia, depression, hypertension, cardiovascular disease (CVD), type 2 diabetes mellitus (T2D), hyperlipidemia, and chronic kidney disease (CKD); previous hospitalizations; CMS risk score; and a number of other medications on the index date.

\section{SENSITIVITY ANALYSIS}

In the sensitivity analysis, patients in all 3 cohorts were required to have at least 2 pharmacy claims for statins, as well as the baseline medications (ACEI/ARBs or OADs or both) to calculate PDC. We ran similar logistic regression models on the cohorts with stricter inclusion criteria.

All statistical analyses were performed using SAS version 9.4 (SAS Institute, Cary, NC) at a priori significance level of 0.05.

\section{Results}

In total,22,925 patients enrolled in the Texas-based Medicare Advantage plan received at least 1 statin prescription during the identification period. Of these, 3,549 were incident statin 


\section{TABLE 1 Baseline Demographic and Clinical Characteristics of the Overall Cohort and by Adherence Group ${ }^{\mathrm{a}}$}

\begin{tabular}{|c|c|c|c|c|}
\hline & \multicolumn{4}{|c|}{ Cohort Ib } \\
\hline & $\begin{array}{l}\text { Total Patients } \\
(\mathrm{N}=1,223)\end{array}$ & $\begin{array}{l}\text { Statin Adherent } \\
\quad(n=509)\end{array}$ & $\begin{array}{c}\text { Statin } \\
\begin{array}{c}\text { Nonadherent } \\
(\mathrm{n}=714)\end{array}\end{array}$ & $P$ Value \\
\hline \multicolumn{5}{|l|}{ Variables } \\
\hline \multicolumn{4}{|l|}{ Gender, n (\%) } & 0.881 \\
\hline Female & $737 \quad(60.3)$ & $308 \quad(60.5)$ & $429 \quad(60.1)$ & \\
\hline Male & $486 \quad(39.7)$ & $201 \quad(39.5)$ & $285 \quad(39.9)$ & \\
\hline \multicolumn{4}{|l|}{ Age, years, n (\%) } & 0.052 \\
\hline$<70$ & $580 \quad(47.4)$ & $259 \quad(50.9)$ & $321 \quad(45.0)$ & \\
\hline $70-79$ & $494 \quad(40.4)$ & 199 (39.1) & $295 \quad(41.3)$ & \\
\hline$\geq 80$ & $149 \quad(12.2)$ & $51 \quad(10.0)$ & $98 \quad(13.7)$ & \\
\hline \multicolumn{4}{|l|}{ Health plan, n (\%) } & 0.051 \\
\hline Low-income subsidy & $618 \quad(50.5)$ & $274 \quad(53.8)$ & 344 (48.2) & \\
\hline No subsidy & $605 \quad(49.5)$ & 235 (46.2) & 370 (51.8) & \\
\hline
\end{tabular}

\section{Comorbidities}

\begin{tabular}{|c|c|c|c|c|c|c|}
\hline \multicolumn{6}{|c|}{ Dementia, n (\%) } & \multirow[t]{2}{*}{0.555} \\
\hline Yes & $48 \quad(3.9)$ & 18 & (3.5) & 30 & $(4.20)$ & \\
\hline No & $1,175 \quad(96.1)$ & 491 & $(96.5)$ & 684 & $(95.80)$ & \\
\hline \multicolumn{6}{|c|}{ Depression, $\mathrm{n}(\%)$} & 0.078 \\
\hline Yes & $208 \quad(17.0)$ & 98 & (19.3) & 110 & $(15.4)$ & \\
\hline No & $1,015 \quad(83.0)$ & 411 & $(80.7)$ & 604 & $(84.6)$ & \\
\hline \multicolumn{6}{|c|}{ CVD, n (\%) } & 0.055 \\
\hline Yes & $393 \quad(32.1)$ & 179 & $(35.2)$ & 214 & $(30.0)$ & \\
\hline No & $830 \quad(67.9)$ & 330 & $(64.8)$ & 500 & $(70.0)$ & \\
\hline \multicolumn{6}{|c|}{ Hypertension, $\mathrm{n}(\%)$} & 0.295 \\
\hline Yes & $1,012 \quad(82.7)$ & 428 & $(84.1)$ & 584 & $(81.8)$ & \\
\hline No & $211 \quad(17.3)$ & 81 & (15.9) & 130 & $(18.2)$ & \\
\hline \multicolumn{6}{|c|}{ T2D, n (\%) } & 0.148 \\
\hline Yes & $667 \quad(54.5)$ & 290 & $(57.0)$ & 377 & $(52.8)$ & \\
\hline No & $556 \quad(45.5)$ & 219 & $(43.0)$ & 337 & $(47.2)$ & \\
\hline
\end{tabular}

\begin{tabular}{|c|c|c|c|c|}
\hline \multicolumn{4}{|c|}{ Hyperlipidemia, n (\%) } & \multirow[t]{2}{*}{0.125} \\
\hline Yes & $954(78.0)$ & $408 \quad(80.2)$ & $546 \quad(76.5)$ & \\
\hline No & $269(22.0)$ & 101 (19.8) & $168 \quad(23.5)$ & \\
\hline \multicolumn{4}{|c|}{ CKD, n (\%) } & 0.456 \\
\hline Yes & $375(30.7)$ & $162(31.8)$ & $213 \quad(29.8)$ & \\
\hline No & $848 \quad(69.3)$ & $347 \quad(68.2)$ & $501 \quad(70.2)$ & \\
\hline \multicolumn{4}{|c|}{ Previous hospitalization, $\mathrm{n}(\%)$} & 0.189 \\
\hline Yes & $78 \quad(6.4)$ & $38 \quad(7.5)$ & $40 \quad(5.6)$ & \\
\hline No & $1,145 \quad(93.6)$ & $471 \quad(92.5)$ & $674 \quad(94.4)$ & \\
\hline
\end{tabular}

continued on next page users. After applying inclusion and exclusion criteria, the baseline ACEI/ ARB user group (cohort I) consisted of 1,223 patients; the OAD user group (cohort II) consisted of 714 patients; and the concomitant ACEI/ARB and OAD user group (cohort III) consisted of 452 patients. Figure 2 illustrates the formation of the 3 cohorts. The mean (SD) age of the sample was 70.25 (8.24) years for cohort I, 69.26 (8.55) years for cohort II, and 69.19 (8.23) years for cohort III. The majority of patients in all cohorts were females, aged $<70$ years, and without previous hospitalizations. Hyperlipidemia, hypertension, and T2D were the most frequent comorbidities in all 3 cohorts. Baseline characteristics were similar between statin adherent and nonadherent groups in all cohorts, except for prevalence of hypertension and hyperlipidemia in cohort II, depression in cohorts II and III, and baseline adherence in all cohorts. The baseline demographics and clinical characteristics are presented separately for each cohort in Table 1. The average (SD) 1-year PDC for statins was $0.68(0.24)$ in cohort I, $0.69(0.23)$ in cohort II, and 0.69 (0.24) in cohort III. Statin adherence proportions were almost similar in all 3 cohorts$41.62 \%, 40.48 \%$, and $42.26 \%$ in cohorts I, II, and III, respectively.

\section{MULTIVARIABLE LOGISTIC REGRESSION ANALYSIS}

Findings from the logistic regression analysis indicate that among all 3 cohorts patients adherent to baseline medication use were significantly more likely to be adherent to future statin use (cohort I: OR $=1.75,95 \%$ $\mathrm{CI}=1.37-2.25$; cohort II: OR $=2.02,95 \%$ $\mathrm{CI}=1.46-2.79$; cohort III: $\mathrm{OR}=1.73,95 \%$ $\mathrm{CI}=1.16-2.58$ ). In cohort $\mathrm{I}$, patients who had low-income subsidies were more likely to be in the statin adherent group compared with patients with no income subsidy $(\mathrm{OR}=1.280$, 


\section{TABLE 1}

Baseline Demographic and Clinical Characteristics of the Overall Cohort and by Adherence Group ${ }^{a}$ (continued)

\begin{tabular}{|c|c|c|c|c|}
\hline & \multicolumn{4}{|c|}{ Cohort $\mathrm{I}^{\mathrm{b}}$} \\
\hline & $\begin{array}{l}\text { Total Patients } \\
\qquad(\mathrm{N}=1,223)\end{array}$ & $\begin{array}{l}\text { Statin Adherent } \\
\qquad(n=509)\end{array}$ & $\begin{array}{c}\text { Statin } \\
\begin{array}{c}\text { Nonadherent } \\
(\mathbf{n}=714)\end{array}\end{array}$ & P Value \\
\hline \multicolumn{4}{|c|}{ Baseline adherence to ACEI/ARB, n (\%) } & $<0.0001$ \\
\hline Yes & $734(60.0)$ & $343(67.4)$ & $391 \quad(54.8)$ & \\
\hline No & $489(40.0)$ & $166(32.6)$ & $323(45.2)$ & \\
\hline
\end{tabular}

Number of other medications on index date

\begin{tabular}{l|c|c|c|c|}
\hline Mean \pm SD & $1.52 \pm 1.84$ & $1.45 \pm 1.77$ & $1.57 \pm 1.90$ & 0.245 \\
\hline CMS risk score & $1.38 \pm 0.99$ & $1.40 \pm 0.99$ & $1.37 \pm 0.99$ & 0.654 \\
\hline Mean \pm SD & \multicolumn{4}{|c|}{ Cohort II } \\
\cline { 2 - 6 } & $\begin{array}{c}\text { Total Patients } \\
(\mathbf{N}=\mathbf{7 1 4 )}\end{array}$ & $\begin{array}{c}\text { Statin Adherent } \\
(\mathbf{n = 2 8 9})\end{array}$ & $\begin{array}{c}\text { Nonadherent } \\
(\mathbf{n}=\mathbf{4 2 5})\end{array}$ & P Value \\
\hline
\end{tabular}

\section{Variables}

\begin{tabular}{|c|c|c|c|c|}
\hline \multicolumn{4}{|l|}{ Gender, n (\%) } & \multirow[t]{2}{*}{0.459} \\
\hline Female & $428 \quad(59.9)$ & $178 \quad(61.6)$ & $250 \quad(58.8)$ & \\
\hline Male & $286(40.1)$ & 111 (38.4) & $175 \quad(41.2)$ & \\
\hline \multicolumn{4}{|l|}{ Age, years, n (\%) } & 0.784 \\
\hline$<70$ & $387 \quad(54.2)$ & $158 \quad(54.7)$ & $229 \quad(53.9)$ & \\
\hline $70-79$ & $246 \quad(34.5)$ & $96 \quad(33.2)$ & $150 \quad(35.3)$ & \\
\hline$\geq 80$ & 81 (11.3) & $35 \quad(12.1)$ & $46 \quad(10.8)$ & \\
\hline \multicolumn{4}{|l|}{ Health plan, n (\%) } & 0.263 \\
\hline Low-income subsidy & $350 \quad(49.0)$ & $149 \quad(51.6)$ & $201 \quad(47.3)$ & \\
\hline No subsidy & $364 \quad(51.0)$ & $140(48.4)$ & $224 \quad(52.7)$ & \\
\hline \multicolumn{5}{|l|}{ Comorbidities } \\
\hline \multicolumn{4}{|l|}{ Dementia, n (\%) } & 0.447 \\
\hline Yes & $16 \quad(2.2)$ & $5 \quad(1.7)$ & $11 \quad(2.6)$ & \\
\hline No & $698 \quad(97.8)$ & $284 \quad(98.3)$ & $414 \quad(97.4)$ & \\
\hline \multicolumn{4}{|l|}{ Depression, n (\%) } & 0.005 \\
\hline Yes & $76 \quad(10.6)$ & 42 (14.5) & $34 \quad(8.0)$ & \\
\hline No & $638 \quad(89.4)$ & $247 \quad(85.5)$ & $391 \quad(92.0)$ & \\
\hline \multicolumn{4}{|l|}{ CVD, n (\%) } & 0.122 \\
\hline Yes & $143(20.0)$ & $66 \quad(22.8)$ & $77 \quad(18.1)$ & \\
\hline No & $571(80.0)$ & 223 (77.2) & $348 \quad(81.9)$ & \\
\hline \multicolumn{4}{|l|}{ Hypertension, $\mathrm{n}(\%)$} & 0.041 \\
\hline Yes & $382 \quad(53.5)$ & $168 \quad(58.1)$ & $214 \quad(50.4)$ & \\
\hline No & $332(46.5)$ & 121 (41.9) & $211 \quad(49.6)$ & \\
\hline
\end{tabular}

continued on next page
95\% CI=1.009-1.624). Further, patients aged $\geq 80$ years were less likely to be adherent to statins compared with those aged $<70$ years $(\mathrm{OR}=0.62,95 \%$ $\mathrm{CI}=0.41-0.92)$. In cohort II, patients with depression had higher odds of being adherent to statins $(\mathrm{OR}=1.83$, 95\% CI=1.08-3.08). Table 2 represents the results from logistic regression analysis.

\section{SENSITIVITY ANALYSIS}

The results of sensitivity analysis showed that the primary explanatory variables among all 3 cohorts remained significant in the regression models using at least 2 pharmacy claims requirement for measuring adherence to statins and baseline medications (cohort I: $\mathrm{OR}=1.70,95 \% \mathrm{CI}=1.31-2.21$; cohort II: $\mathrm{OR}=2.22 ; 95 \% \mathrm{CI}=1.57-3.13$; cohort III: OR=1.79, 95\% CI=1.17-2.73).

\section{Discussion}

Results from this study indicate that among patients enrolled in a Texas Medicare Advantage plan, statin adherence rate within a year of treatment initiation is low (less than 50\%). This finding aligns with the existing literature. ${ }^{12-17}$ According to a recent systematic review, being a new statin user along with other factors, such as age, sex, race, socioeconomic status, side effects, and comorbidities, are potential reasons for statin nonadherence. ${ }^{47}$ Further, our findings revealed that previous adherence to ACEIs/ARBs and OADs was significantly associated with adherence to newly initiated statins over the first 12 months of treatment. We found that patients who were adherent to ACEI/ARB use, OAD use, or both in the past had higher likelihood of being adherent to statins in the first year of treatment initiation.

The result of this study is consistent with previous findings. A 2018 study indicated that baseline adherence to 


\section{TABLE 1 Baseline Demographic and Clinical Characteristics of the Overall Cohort and by Adherence Group ${ }^{\text {a }}$ (continued)}

\begin{tabular}{|c|c|c|c|c|}
\hline \multirow{2}{*}{} & \multicolumn{4}{|c|}{ Cohort IIc } \\
\cline { 2 - 5 } & $\begin{array}{c}\text { Total Patients } \\
(\mathbf{N}=714)\end{array}$ & $\begin{array}{c}\text { Statin Adherent } \\
(\mathbf{n}=289)\end{array}$ & $\begin{array}{c}\text { Statin } \\
\text { Nonadherent } \\
(\mathbf{n}=425)\end{array}$ & P Value \\
\hline
\end{tabular}

\section{Comorbidities}

\begin{tabular}{|c|c|c|c|c|}
\hline \multicolumn{4}{|c|}{ T2D, n (\%) } & \multirow[t]{2}{*}{0.067} \\
\hline Yes & $388 \quad(54.3)$ & $120(41.5)$ & $219 \quad(51.5)$ & \\
\hline No & $326 \quad(45.7)$ & $169(58.5)$ & $206(48.5)$ & \\
\hline \multicolumn{4}{|c|}{ Hyperlipidemia, n (\%) } & 0.018 \\
\hline Yes & $362(50.7)$ & $162(56.1)$ & $200 \quad(47.1)$ & \\
\hline No & $352(49.3)$ & $127(43.9)$ & $225 \quad(52.9)$ & \\
\hline \multicolumn{4}{|c|}{ CKD, n (\%) } & 0.452 \\
\hline Yes & 141 (19.8) & $61(21.1)$ & $80(18.8)$ & \\
\hline No & $573(80.2)$ & $228(78.9)$ & $345(81.2)$ & \\
\hline \multicolumn{4}{|c|}{ Previous hospitalization, n (\%) } & 0.246 \\
\hline Yes & $52 \quad(7.3)$ & $25 \quad(8.7)$ & $27 \quad(6.4)$ & \\
\hline No & $662(92.7)$ & $264(91.3)$ & $398 \quad(93.6)$ & \\
\hline \multicolumn{4}{|c|}{ Baseline adherence to ACEI/ARB, n (\%) } & $<0.0001$ \\
\hline Yes & $427 \quad(59.8)$ & $200 \quad(69.2)$ & $227 \quad(53.4)$ & \\
\hline No & 287 (40.2) & $89 \quad(30.8)$ & 198 (46.6) & \\
\hline
\end{tabular}

Number of other medications on index date

\begin{tabular}{l|c|c|c|c|}
\hline Mean \pm SD & $1.65 \pm 1.84$ & $1.56 \pm 1.76$ & $1.71 \pm 1.90$ & 0.291 \\
\hline CMS risk score & $1.45 \pm 0.98$ & $1.45 \pm 0.95$ & $1.45 \pm 1.00$ & 0.942 \\
\hline Mean \pm SD & \multicolumn{4}{|c|}{ Cohort III } \\
\cline { 2 - 6 } & $\begin{array}{c}\text { Total Patients } \\
(\mathbf{N}=\mathbf{4 5 2})\end{array}$ & $\begin{array}{c}\text { Statin Adherent } \\
(\mathbf{n}=\mathbf{1 9 1})\end{array}$ & $\begin{array}{c}\text { Statin } \\
\text { Nonadherent } \\
(\mathbf{n}=\mathbf{2 6 1})\end{array}$ & P Value \\
\hline
\end{tabular}

\section{Variables}

\begin{tabular}{l|ll|l|l|l}
\hline \multicolumn{6}{|l|}{ Gender, $\mathbf{n}(\%)$} \\
\hline Female & $264(58.4)$ & $118(61.8)$ & $146(55.9)$ & 0.213 \\
\hline Male & $188(41.6)$ & $73(38.2)$ & $115(44.1)$ & \\
\hline
\end{tabular}

\begin{tabular}{l|rl|r|rr|r}
\hline Age, years, $\mathbf{n}(\%)$ & 0.181 \\
\hline$<70$ & $243(53.7)$ & $111(58.1)$ & $132(50.6)$ & \\
\hline $70-79$ & $164(36.3)$ & $60(31.4)$ & $104(39.8)$ & \\
\hline$\geq 80$ & $45(10.0)$ & $20(10.5)$ & 25 & $(9.6)$ & \\
\hline
\end{tabular}

\begin{tabular}{l|ll|l|l|l|l}
\hline Health plan, $\mathbf{n}(\%)$ & & & 0.408 \\
\hline Low-income subsidy & 224 & $(49.6)$ & $99(51.8)$ & $125(47.9)$ & \\
\hline No subsidy & 228 & $(50.4)$ & $92(48.2)$ & $136 \quad(52.1)$ & \\
\hline
\end{tabular}

continued on next page chronic medications was a relatively strong predictor of future adherence to newly initiated statins and it is best measured by mean PDC. ${ }^{36}$ However, the 2018 study used a broad range of medications as baseline adherence measurements in the primary analysis of the study. Similarly, Muntner et al. (2014) described low adherence to past antihypertensive medications as a strong predictor for future statin discontinuation and poor adherence using average PDC across drug classes that include ACEIs, ARBs, beta blockers, calcium channel blockers, and diuretics. ${ }^{35}$ By grouping patients into 3 separate cohorts using specific drug classes for baseline adherence measurements, our study attempted to reduce some of the potential biases caused by different safety and efficacy profiles affecting patient's adherence and determine the association between past adherence and future statin adherence in a more homogeneous group.

Another study by Franklin et al. (2015) predicted adherence trajectories for 1 year after statin initiation using the initial 2-4 months filling indicator. ${ }^{34}$ Although they found that initial adherence is a strong and useful tool to predict future adherence pattern over baseline clinical characteristics alone, they did not take into account the effect of past adherence to other chronic medications on future adherence to newly initiated statins. ${ }^{34}$

According to our study, patients aged $\geq 80$ years were less likely to be in the statin adherent group as compared with those aged $<70$ years. The association between age and adherence is still controversial; however, our results are consistent with studies concluding that medication adherence is adversely affected by age. ${ }^{29,48}$ Potential reasons for nonadherence among older adults could be the development of cognitive 


\section{TABLE 1 Baseline Demographic and Clinical Characteristics of the Overall Cohort and by Adherence Group ${ }^{a}$ (continued)}

\begin{tabular}{|c|c|c|c|c|}
\hline & & Cohort & III $\mathrm{d}^{\mathrm{d}}$ & \\
\hline & $\begin{array}{l}\text { Total Patients } \\
\quad(\mathrm{N}=452)\end{array}$ & $\begin{array}{l}\text { Statin Adherent } \\
\quad(n=191)\end{array}$ & $\begin{array}{c}\text { Statin } \\
\text { Nonadherent } \\
(n=261)\end{array}$ & P Value \\
\hline Comorbiditi & & & & \\
\hline Dementia, $n$ & & & & 0.364 \\
\hline Yes & $16 \quad(3.5)$ & $5 \quad(2.6)$ & $11 \quad(4.2)$ & \\
\hline No & $436 \quad(96.5)$ & $186 \quad(97.4)$ & $250 \quad(95.8)$ & \\
\hline Depression, & & & & 0.026 \\
\hline Yes & 72 (15.9) & $39(20.4)$ & 33 (12.6) & \\
\hline No & 380 (84.1) & $152(79.6)$ & $228 \quad(87.4)$ & \\
\hline CVD, n (\%) & & & & 0.599 \\
\hline Yes & $136(30.1)$ & $60 \quad(31.4)$ & $76 \quad(29.1)$ & \\
\hline No & $316 \quad(69.9)$ & 131 (68.6) & 185 (70.9) & \\
\hline Hypertensic & & & & 0.367 \\
\hline Yes & 370 (81.9) & $160(83.8)$ & $210 \quad(80.5)$ & \\
\hline No & $82 \quad(18.1)$ & $31 \quad(16.2)$ & $51 \quad(19.5)$ & \\
\hline T2D, n (\%) & & & & 0.590 \\
\hline Yes & $376 \quad(83.2)$ & $161(84.3)$ & $215 \quad(82.4)$ & \\
\hline No & $76 \quad(16.8)$ & $30 \quad(15.7)$ & $46 \quad(17.6)$ & \\
\hline Hyperlipide & & & & 0.164 \\
\hline Yes & $350 \quad(77.4)$ & $154 \quad(80.6)$ & $196(75.1)$ & \\
\hline No & 102 (22.6) & $37 \quad(19.4)$ & $65 \quad(24.9)$ & \\
\hline CKD, n (\%) & & & & 0.828 \\
\hline Yes & $135 \quad(29.9)$ & $56 \quad(29.3)$ & $79 \quad(30.3)$ & \\
\hline No & 317 (70.1) & 135 (70.7) & 182(69.7) & \\
\hline Previous ho & , n (\%) & & & 0.772 \\
\hline Yes & $29 \quad(6.4)$ & $13 \quad(6.8)$ & $16 \quad(6.1)$ & \\
\hline No & $423 \quad(93.6)$ & $178 \quad(93.2)$ & $245 \quad(93.9)$ & \\
\hline Baseline ad & ACEI/ARB, n (\%) & & & 0.008 \\
\hline Yes & $204 \quad(45.1)$ & $100 \quad(52.4)$ & $104 \quad(39.9)$ & \\
\hline No & $248 \quad(54.9)$ & 91 (47.6) & $157 \quad(60.1)$ & \\
\hline Number of & ations on index & & & \\
\hline Mean \pm SD & $1.67 \pm 1.84$ & $1.69 \pm 1.90$ & $1.67 \pm 1.80$ & 0.906 \\
\hline CMS risk scC & & & & \\
\hline Mean \pm SD & $1.45 \pm 1.04$ & $1.42 \pm 0.99$ & $1.47 \pm 1.07$ & 0.599 \\
\hline
\end{tabular}

asignificant $P$ values from chi-square and $t$-tests $<0.05$.

${ }^{b}$ ACEI/ARB users.

'OAD users.

${ }^{d}$ Concomitant ACEI/ARB and OAD users.

$A C E I=$ angiotensin-converting enzyme inhibitors; $A R B=$ angiotensin II receptor blockers; $C K D=$ chronic

kidney disease; $C M S=$ Centers for Medicare \& Medicaid Services; $C V D=$ cardiovascular disease; $O A D=$ oral antidiabetic drug; $S D=$ standard deviation; $T 2 D=$ type 2 diabetes. impairments, multiple comorbid conditions, complex treatment regimens, and higher adverse effects over time..$^{49}$

Another finding from the present study was that patients with depression had a higher likelihood of being adherent to statins. Existing literature provides varied findings regarding the association between adherence and depression. ${ }^{50-54}$ A potential reason is that medication adherence is influenced by the severity of depression and depressive symptoms experienced by patients. Patients diagnosed with depression who are in remission due to antidepressant use may have improved medication adherence. However, we did not measure antidepressant use and depression severity, since the association was beyond the scope of the current study.

The last significant finding from our analysis was that patients receiving low-income subsidies were more likely to be adherent to statins compared with those with no income subsidy. This association is in accordance with a previous study that revealed that low-income subsidy beneficiaries from a Medicare Part D plan had lower out-of-pocket costs, higher medication fills, and better adherence. ${ }^{55}$ However, we only found this significant association in the cohort of ACEI/ARB users.

The variables of gender; comorbidities (e.g., dementia, CVD, hypertension, T2D, hyperlipidemia, and CKD); previous hospitalization; number of other medications on the index date; and CMS risk score were not found to be significantly associated with the study outcome variable in any of the cohorts. According to a systematic review, females are less likely to be adherent to statins. ${ }^{56}$ However, the current study did not find a significant difference in statin adherence across gender, which may be due to the new statin user population, as well as the limited follow-up time in this study. 


\section{TABLE 2 Multivariable Logistic Regression for Statin Adherent Group Versus Statin Nonadherent Group ${ }^{\mathrm{a}}$}

\begin{tabular}{|c|c|c|c|c|c|c|}
\hline \multirow[b]{3}{*}{ Variable } & \multicolumn{6}{|c|}{ Statin Adherent vs. Nonadherent } \\
\hline & \multicolumn{2}{|c|}{ Cohort Ib $(n=1,223)$} & \multicolumn{2}{|c|}{ Cohort IIC $(n=714)$} & \multicolumn{2}{|c|}{ Cohort III $(n=452)$} \\
\hline & aOR $(95 \% \mathrm{Cl})$ & P Value & aOR $(95 \% \mathrm{Cl})$ & P Value & aOR $(95 \% \mathrm{Cl})$ & P Value \\
\hline \multicolumn{7}{|l|}{ Baseline medication adherence } \\
\hline Adherence vs. nonadherence & $1.75 \quad(1.37-2.25)$ & $<0.0001$ & $2.02(1.46-2.79)$ & $<0.0001$ & $1.73 \quad(1.16-2.58)$ & 0.006 \\
\hline \multicolumn{7}{|l|}{ Gender } \\
\hline Female vs. male & $0.97 \quad(0.76-1.24)$ & 0.847 & 1.08 (0.79-1.49) & 0.604 & $1.20 \quad(0.80-1.79)$ & 0.365 \\
\hline \multicolumn{7}{|l|}{ Age, years } \\
\hline $70-79$ vs. $<70$ & $0.84(0.65-1.08)$ & 0.629 & $0.89 \quad(0.63-1.26)$ & 0.331 & $0.73 \quad(0.47-1.12)$ & 0.141 \\
\hline$\geq 80$ vs. $<70$ & $0.62 \quad(0.41-0.92)$ & 0.041 & $1.14 \quad(0.69-1.91)$ & 0.434 & $1.07 \quad(0.55-2.11)$ & 0.480 \\
\hline \multicolumn{7}{|l|}{ Health plan } \\
\hline Having low-income subsidy vs. not & $1.28(1.009-1.624)$ & 0.042 & $1.22(0.89-1.68)$ & 0.213 & $1.24 \quad(0.83-1.85)$ & 0.285 \\
\hline \multicolumn{7}{|l|}{ Comorbidities } \\
\hline \multicolumn{7}{|l|}{ Dementia } \\
\hline Yes vs. no & $0.89(0.48-1.67)$ & 0.732 & $0.58 \quad(0.19-1.77)$ & 0.340 & $0.58 \quad(0.19-1.80)$ & 0.355 \\
\hline \multicolumn{7}{|l|}{ Depression } \\
\hline Yes vs. no & $1.20 \quad(0.87-1.65)$ & 0.264 & $1.83(1.08-3.08)$ & 0.024 & $1.68 \quad(0.97-2.90)$ & 0.060 \\
\hline \multicolumn{7}{|l|}{ CVD } \\
\hline Yes vs. no & $1.30 \quad(0.99-1.71)$ & 0.057 & $1.33 \quad(0.85-2.10)$ & 0.208 & $1.23 \quad(0.77-1.95)$ & 0.378 \\
\hline \multicolumn{7}{|l|}{ Hypertension } \\
\hline Yes vs. no & $0.78 \quad(0.44-1.38)$ & 0.407 & $0.96 \quad(0.25-3.72)$ & 0.961 & $0.93 \quad(0.24-3.63)$ & 0.923 \\
\hline \multicolumn{7}{|l|}{ T2D } \\
\hline Yes vs. no & $1.11 \quad(0.85-1.46)$ & 0.415 & $0.63 \quad(0.17-2.27)$ & 0.483 & $0.59 \quad(0.16-2.22)$ & 0.442 \\
\hline \multicolumn{7}{|l|}{ Hyperlipidemia } \\
\hline Yes vs. no & $1.33 \quad(0.81-2.19)$ & 0.259 & $2.05(0.86-4.86)$ & 0.101 & $2.06 \quad(0.87-4.90)$ & 0.100 \\
\hline \multicolumn{7}{|l|}{ CKD } \\
\hline Yes vs. no & $1.01 \quad(0.77-1.33)$ & 0.895 & $0.87 \quad(0.55-1.37)$ & 0.561 & $0.85 \quad(0.53-1.35)$ & 0.499 \\
\hline \multicolumn{7}{|l|}{ Previous hospitalization } \\
\hline Yes vs. no & $1.36 \quad(0.82-2.28)$ & 0.227 & $1.64(0.86-3.12)$ & 0.128 & $1.51 \quad(0.60-3.74)$ & 0.373 \\
\hline Number of other medications on index date & $0.96 \quad(0.90-1.02)$ & 0.251 & $0.95 \quad(0.87-1.03)$ & 0.264 & $0.99 \quad(0.89-1.10)$ & 0.949 \\
\hline CMS risk score & $1.00(0.87-1.14)$ & 0.974 & $0.92 \quad(0.77-1.11)$ & 0.414 & $0.92 \quad(0.73-1.16)$ & 0.493 \\
\hline
\end{tabular}

asignificant $P<0.05$.

${ }^{\mathrm{D} A C E I / A R B}$ users.

'OAD users.

${ }^{\mathrm{C} C}$ Concomitant ACEI/ARB and OAD users.

$A C E I=$ angiotensin-converting enzyme inhibitors; $A R B=$ angiotensin II receptor blockers; $a O R=$ adjusted odds ratio; $C l=$ confidence interval; $C K D=c h r o n i c$ kidney disease; $C M S=$ Centers for Medicare \& Medicaid Services; $C V D=$ cardiovascular disease; $O A D=$ oral antidiabetic drug; $T 2 D=$ type 2 diabetes.

A number of other medications could affect adherence in two directions, and hence the overall pattern for the association is still not clear. ${ }^{29}$ While some patients may have better medication-taking behavior with increased pill burden and higher level of knowledge about their health status ${ }^{57}$ others may find medication adherence more difficult with concurrent use of multiple medications. ${ }^{58}$ With respect to the other variables, previous literature assessing factors associated with statin adherence mostly provide inconsistent results that may be due to heterogeneity of the 
study population, insufficient sample size, and using different adherence measures. ${ }^{28,29}$

\section{LIMITATIONS}

Our findings should be interpreted in light of some limitations. First, the data available for the present study lacked information for some sociodemographic variables such as race or education, which could be potential confounders.

Second, adherence was calculated from pharmacy claims that only reflect prescription-filling behavior and not actual medication-taking patterns.

Third, pharmacy claim data did not allow for the assessment of the reasons for medication nonadherence or discontinuation. Statin therapy may be discontinued appropriately by physicians due to adverse effects, frailty, comorbidity, and polypharmacy, especially in the very elderly population, considering the limited benefit to and life expectancy of these patients. ${ }^{59}$ However, by excluding patients with potential precautions or contraindicated use, we expected to have a low number of patients with poor medication adherence due to serious adverse effects.

Fourth, although $0.80 \mathrm{PDC}$ is a commonly accepted cut-off point for measuring adherence, we may have lost some information by creating a binary variable.

Finally, the generalizability of the results of this study is limited, since it was conducted among patients enrolled in a Medicare Advantage plan based in Texas. Given that the majority of patients enrolled in Medicare Advantage plans are from the elderly population, our findings could not be generalized to younger adults. Therefore, future studies should evaluate the generalizability of the results in patients with different age groups, insurance providers, and from different geographical areas.

\section{Conclusions}

This study demonstrated that, among patients enrolled in a Medicare Advantage plan, adherence to past medication used for chronic conditions such as ACEIs, ARBs, and OADs is associated with future adherence to newly initiated statins. Given that medication adherence is a modifiable health behavior, identifying patients at a higher risk of becoming nonadherent at the time of treatment initiation could enable health care providers and payers to identify barriers early on, develop targeted intervention plans, and enhance future adherence to statin therapy.

\section{DISCLOSURES}

No funding was received for this study. Abughosh reports grants from RegeneronSanofi, BMS-Pfizer, and Valeant, unrelated to this work. Majd, Mohan, and Paranjpe have nothing to disclose.

\section{REFERENCES}

1. Salami JA, Warraich H, Valero-Elizondo J, et al. National trends in statin use and expenditures in the U.S. adult population from 2002 to 2013: insights from the Medical Expenditure Panel Survey. JAMA Cardiol. 2017;2(1):56-65.

2. Salami JA, Warraich HJ, Valero-Elizondo J, et al. National trends in nonstatin use and expenditures among the US adult population from 2002 to 2013: insights from medical expenditure panel survey. J Am Heart Assoc. 2018;7(2):e007132.

3. Arnett DK, Blumenthal RS, Albert MA, et al. 2019 ACC/AHA guideline on the primary prevention of cardiovascular disease: executive summary: a report of the American College of Cardiology/American Heart Association Task Force on Clinical Practice Guidelines. J Am Coll Cardiol. 2019;74(10):1376-414.
4. Benjamin EJ, Muntner P, Alonso A, et al. Heart disease and stroke statistics-2019 update: a report from the American Heart Association. Circulation. 2019;139(10):e56-e528.

5. Trialists CT. Efficacy and safety of cholesterol-lowering treatment: prospective meta-analysis of data from 90,056 participants in 14 randomised trials of statins. Lancet. 2005;366(9493):1267-78.

6. Consumer Reports Health. Best buy drugs. Evaluating statin drugs to treat: high cholesterol and heart disease: comparing effectiveness, safety, and price. June 2010. Accessed December 29, 2020. http://www.khpi.org/dwnlds/2012/ ConsumerReportStatin2010.pdf

7. Thavendiranathan P, Bagai A, Brookhart MA, Choudhry NK. Primary prevention of cardiovascular diseases with statin therapy: a meta-analysis of randomized controlled trials. Arch Intern Med. 2006;166(21):2307-13.

8. Cheung BM, Lauder IJ, Lau CP, Kumana CR. Meta-analysis of large randomized controlled trials to evaluate the impact of statins on cardiovascular outcomes. Br J Clin Pharmacol. 2004;57(5):640-51.

9. Trialists CT. Efficacy and safety of more intensive lowering of LDL cholesterol: a meta-analysis of data from 170000 participants in 26 randomised trials. Lancet. 2010;376(9753):1670-81.

10. Trialists CT. The effects of lowering LDL cholesterol with statin therapy in people at low risk of vascular disease: meta-analysis of individual data from 27 randomised trials. Lancet. 2012;380(9841):581-90.

11. Trialists CT. Efficacy and safety of LDL-lowering therapy among men and women: meta-analysis of individual data from 174,000 participants in 27 randomised trials. Lancet. 2015;385(9976): 1397-405.

12. Vadhariya A, Fleming ML, Johnson ML, et al. Group-based trajectory models to identify sociodemographic and clinical predictors of adherence patterns to statin therapy among older adults. Am Health Drug Benefits. 2019;12(4):202-11. 
13. Benner JS, Glynn RJ, Mogun H, Neumann PJ, Weinstein MC, Avorn J. Long-term persistence in use of statin therapy in elderly patients. JAMA. 2002;288(4):455-61.

14. Jackevicius CA, Li P, Tu JV. Prevalence, predictors, and outcomes of primary nonadherence after acute myocardial infarction. Circulation. 2008;117(8):1028-36.

15. Lemstra M, Blackburn D, Crawley A, Fung R. Proportion and risk indicators of nonadherence to statin therapy: a metaanalysis. Can J Cardiol. 2012;28(5):574-80.

16. Vinker S, Shani M, Baevsky T, Elhayany A. Adherence with statins over 8 years in a usual care setting. Am J Manag Care. 2008;14(6):388-92.

17. Zhang H, Plutzky J, Skentzos S, et al. Discontinuation of statins in routine care settings: a cohort study. Ann Intern Med. 2013;158(7):526-34.

18. Ruppar T, Ho PM, Garber L, et al. Overcoming barriers to medication adherence for chronic diseases. Centers for Disease Contron and Prevention. February 21, 2017. Accessed December 29, 2020. https://www.cdc.gov/ grand-rounds/pp/2017/20170221-medication-adherence.html

19. Sabaté E, ed. Adherence to Long-Term Therapies: Evidence for Action. World Health Organization; 2003. Accessed December 29, 2020. https://www.who. int/chp/knowledge/publications/adherence_full_report.pdf

20. Kripalani S, Yao X, Haynes RB. Interventions to enhance medication adherence in chronic medical conditions: a systematic review. Arch Intern Med. 2007;167(6):540-49.

21. Peterson AM, Takiya L, Finley R. Meta-analysis of trials of interventions to improve medication adherence. Am J Health Syst Pharm. 2003;60(7):657-65.

22. Conn VS, Hafdahl AR, Cooper PS, Ruppar TM, Mehr DR, Russell CL. Interventions to improve medication adherence among older adults: meta-analysis of adherence outcomes among randomized controlled trials. Gerontologist. 2009;49(4):447-62.
23. Viswanathan M, Golin CE, Jones CD, et al. Interventions to improve adherence to self-administered medications for chronic diseases in the United States: a systematic review. Ann Intern Med. 2012;157(11):785-95.

24. Williams A, Manias E, Walker R. Interventions to improve medication adherence in people with multiple chronic conditions: a systematic review. J Adv Nurs. 2008;63(2):132-43.

25. Dillon P, Stewart D, Smith SM, Gallagher P, Cousins G. Group-based trajectory models: assessing adherence to antihypertensive medication in older adults in a community pharmacy setting. Clin Pharmacol Ther. 2018;103(6):1052-60.

26. Rash JA, Campbell DJ, Tonelli M, Campbell TS. A systematic review of interventions to improve adherence to statin medication: what do we know about what works? Prev Med. 2016;90:155-69.

27. Cutrona SL, Choudhry NK, Fischer MA, et al. Targeting cardiovascular medication adherence interventions. J Am Pharm Assoc. 2012;52(3):381-97.

28. Mann DM, Allegrante JP, Natarajan S, Halm EA, Charlson M. Predictors of adherence to statins for primary prevention. Cardiovasc Drugs Ther. 2007;21(4):311-16.

29. Mann DM, Woodward M, Muntner P, Falzon L, Kronish I. Predictors of nonadherence to statins: a systematic review and meta-analysis. Ann Pharmacother. 2010;44(9):1410-21.

30. Choudhry NK, Fischer MA, Avorn J, et al. The implications of therapeutic complexity on adherence to cardiovascular medications. Arch Intern Med. 2011;171(9):814-22.

31. Steiner JF. Can we identify clinical predictors of medication adherence... and should we? Med Care. 2010;48(3):193-95.

32. Franklin JM, Shrank WH, Lii J, et al. Observing versus predicting: initial patterns of filling predict long-term adherence more accurately than highdimensional modeling techniques. Health Serv Res. 2016;51(1):220-39.
33. Molfenter TD, Bhattacharya A, Gustafson DH. The roles of past behavior and health beliefs in predicting medication adherence to a statin regimen. Patient Prefer Adherence. 2012;6:643-51.

34. Franklin JM, Krumme AA, Shrank WH, Matlin OS, Brennan TA, Choudhry NK. Predicting adherence trajectory using initial patterns of medication filling. Am J Manag Care. 2015;21(9):e537-e544.

35. Muntner P, Yun H, Sharma P, et al. Ability of low antihypertensive medication adherence to predict statin discontinuation and low statin adherence in patients initiating treatment after a coronary event. Am J Cardiol. 2014;114(6):826-31.

36. Kumamaru H, Lee MP, Choudhry NK, et al. Using previous medication adherence to predict future adherence. J Manag Care Spec Pharm. 2018;24(11):1146-55. doi: 10.18553/jmcp.2018.24.11.1146

37. Krumme AA, Franklin JM, Isaman DL, et al. Predicting 1-year statin adherence among prevalent users: a retrospective cohort study. J Manag Care Spec Pharm. 2017;23(4):494-502. doi: 10.18553/ jmcp.2017.23.4.494

38. Owen JA. Medicare star ratings: stakeholder proceedings on community pharmacy and managed care partnerships in quality: American Pharmacists Association and Academy of Managed Care Pharmacy. J Am Pharm Assoc. 2014;54(3):228-40.

39. Centers for Medicare \& Medicaid Services. Medicare 2019 Part C and D star ratings technical notes. Updated March 21 2019. Accessed January 7, 2021. https://www.cms. gov/Medicare/Prescription-DrugCoverage/PrescriptionDrugCovGenIn/ Downloads/2019-Technical-Notes.pdf

40. Peterson AM, Nau DP, Cramer JA, Benner J, Gwadry-Sridhar F, Nichol M. A checklist for medication compliance and persistence studies using retrospective databases. Value Health. 2007;10(1):3-12.

41. Nau DP. Proportion of days covered (PDC) as a preferred method of measuring medication adherence. 2012. Accessed December 29, 2020. http://ep.yimg.com/ ty/cdn/epill/pdcmpr.pdf 
42. Choudhry NK, Shrank WH, Levin RL, et al. Measuring concurrent adherence to multiple related medications. Am J Manag Care. 2009;15(7):457-64.

43. Babitsch B, Gohl D, Von Lengerke T. Re-revisiting Andersen's Behavioral Model of Health Services Use: a systematic review of studies from 1998-2011. Psychosoc Med. 2012;9:Doc 11.

44. Wang X, Chen H, Essien E, et al. Medication adherence to antihypertensive triple-combination therapy among patients enrolled in a medicare advantage plan. J Manag Care Spec Pharm. 2019;25(6):678-86. doi: 10.18553/ jmcp.2019.25.6.678

45. Johnson ML, Parikh N, Kunik ME, et al. Antihypertensive drug use and the risk of dementia in patients with diabetes mellitus. Alzheimers Dement. 2012;8(5):437-44.

46. Parikh NM, Morgan RO, Kunik ME, et al. Risk factors for dementia in patients over 65 with diabetes. Int J Geriatr Psychiatry. 2011;26(7):749-57.

47. Ingersgaard MV, Andersen TH, Norgaard O, Grabowski D, Olesen K. Reasons for nonadherence to statins-a systematic review of reviews. Patient Prefer Adherence. 2020;14:675-91.
48. Kulkarni SP, Alexander KP, Lytle B, Heiss G, Peterson ED. Long-term adherence with cardiovascular drug regimens. Am Heart J. 2006;151(1):185-91.

49. Dunbar-Jacob J, Mortimer-Stephens M. Treatment adherence in chronic disease. J Clin Epidemiol. 2001;54(Suppl 1):S57-S60.

50. Aarnio E, Martikainen J, Winn AN, Huupponen R, Vahtera J, Korhonen MJ. Socioeconomic inequalities in statin adherence under universal coverage: does sex matter? Circulation. 2016;9(6):704-13.

51. Stilley CS, Sereika S, Muldoon MF, Ryan CM, Dunbar-Jacob J. Psychological and cognitive function: predictors of adherence with cholesterol lowering treatment. Ann Behav Med. 2004;27(2):117-24.

52. Al-Foraih M, Somerset S. Factors affecting adherence to statins in hypercholesterolemic Kuwaiti patients: a cross-sectional study. Med Princ Pract. 2017;26(1):35-40.

53. Rublee DA, Chen S-Y, Mardekian J, $\mathrm{Wu}$ N, Rao P, Boulanger L. Evaluation of cardiovascular morbidity associated with adherence to atorvastatin therapy. Am J Ther. 2012;19(1):24-32.
54. Perreault S, Dragomir A, Blais L, et al. Impact of better adherence to statin agents in the primary prevention of coronary artery disease. Eur J Clin Pharmacol. 2009;65(10):1013-24.

55. Yala SM, Duru OK, Ettner SL, Turk N, Mangione CM, Brown AF. Patterns of prescription drug expenditures and medication adherence among medicare part D beneficiaries with and without the lowincome supplement. BMC Health Serv Res. 2014;14(1):665.

56. Lewey J, Shrank WH, Bowry AD, Kilabuk E, Brennan TA, Choudhry NK. Gender and racial disparities in adherence to statin therapy: a meta-analysis. Am Heart J. 2013;165(5):665-78.e661.

57. Horne R, Weinman J. Patients' beliefs about prescribed medicines and their role in adherence to treatment in chronic physical illness. J Psychosom Res. 1999;47(6):555-67.

58. Shalansky SJ, Levy AR. Effect of number of medications on cardiovascular therapy adherence. Ann Pharmacother. 2002;36(10):1532-39.

59. Mortensen MB, Falk E. Primary prevention with statins in the elderly. J Am Coll Cardiol. 2018;71(1):85-94. 